Thorax 1986;41:812-813

\title{
Resuscitative laser photoresection of a tracheal tumour before elective surgery
}

\author{
P J M GEORGE, C P O GARRETT, P GOLDSTRAW, M R HETZEL, A D RAMSAY
}

From University College Hospital, London

The palliative role of the neodymium yttrium-aluminiumgarnet (Nd YAG) laser in the management of tracheobronchial tumours is already established. ${ }^{12}$ We report a patient with a tracheal tumour, nearly occluding the lumen, in whom laser photoresection restored an adequate airway and thereby facilitated elective surgery.

\section{Case report}

A 66 year old man was admitted to another hospital with a four month history of breathlessness, non-productive cough, and weight loss of nearly $4 \mathrm{~kg}$. He had smoked up to 20 cigarettes a day before stopping 18 years previously. He had inspiratory stridor and, although his chest radiograph appeared normal, tomography showed a tumour in the lower trachea. Despite treatment with oral prednisolone, the tracheal obstruction was judged to be too severe for radiotherapy to act sufficiently quickly. He was therefore referred for urgent palliation with laser photoresection.

On admission to this hospital, he was centrally cyanosed and in obvious respiratory distress. Examination showed inspiratory stridor and widespread coarse crackles from retained secretions. The peak expiratory flow (PEF) was $801 \mathrm{~min}^{-1}$. Fibreoptic bronchoscopy showed an intraluminal tumour nearly occluding the lumen. It was about $2 \mathrm{~cm}$ in length and the lower margin was $1.5 \mathrm{~cm}$ above the main carina.

In view of the patient's critical condition he proceeded immediately to photoresection with the Nd YAG laser. In one treatment, in which both rigid and fibreoptic bronchoscopes were used under general anaesthesia, ${ }^{2}$ it was possible to re-establish about $60 \%$ of the tracheal lumen. This immediately abolished his stridor and the PEF rose to $2401 \mathrm{~min}^{-1} 12$ hours after he had recovered from the anaesthetic. Despite a chest infection, which required treatment with antibiotics, he continued to improve and after 17 days the PEF was $4901 \mathrm{~min}^{-1}$, the $\mathrm{FEV}_{1} 2.75 \mathrm{l}$, and the forced vital capacity 3.911 .

This great improvement allowed an assessment of the operability of the tumour. Oesophagoscopy and isotope bone scanning showed normal appearances. Computed tomography of the chest and abdomen showed the residual tumour but no evident metastatic disease. Rigid bronchoscopy confirmed that the tumour was surgically resectable, although the adjacent tracheal wall appeared to be inflamed as a result of infection and previous trauma.

Address for reprint requests: Dr P J M George, University College Hospital, London WC1E 6AU.

Accepted 17 February 1986
Biopsy specimens were not conclusive but suggested a diag nosis of squamous cell carcinoma.

Surgical treatment was deferred for one month until ster oid treatment had been withdrawn and complete resolution $\vec{b}$ of infection and inflammation had been confirmed by furtheoo rigid bronchoscopy. A right thoracotomy was performe and $3 \mathrm{~cm}$ of trachea was excised at $1 \mathrm{~cm}$ above the carina, to give a complete macroscopic clearance of the tumour. Venti lation was maintained with an endotracheal tube in the lefo main bronchus. The tracheal margins were found to be cleap of tumour at frozen section and were anastomosed. Mediaso tinal glands adjacent to the tumour appeared indurated, bu霖 no secondary tumour was found on histological examination. The patient made an uneventful recovery and haso since remained completely well during seven months.

Inspection of the resected specimen at low power showe that the tumour had an overall nodular architecture and ha penetrated through the tracheal wall. Histological exam? ination revealed epithelial areas, some of which showed squamous differentiation (fig $1 a$ ), together with myxoif spindle cell areas (fig $1 b$ ). The appearance resembled that of a mixed salivary gland tumour (pleomorphic adenoma), bu both epithelial and spindle elements were judged to be malig nant on the basis of destruction and infiltration of adjacent soft tissue and cartilage (fig $2 a$ ). The results of immunơ. cytochemical studies using anticytokeratin (CAM 5.2), ${ }^{3}$ antî S100 protein, ${ }^{4}$ and antivimentin antibodies ${ }^{5}$ were como patible with a pleomorphic adenoma. ${ }^{6}$ Further evidence the similarity of this tumour to tumours of salivary glands was provided by the presence of tyrosine crystals within the tumour cells and stroma (fig $2 b$ ). The lesion therefore fulfilled the criteria of a malignant mixed tumour ${ }^{7}$ and was presumed to have arisen from tracheal glands.

\section{Discussion}

Intraluminal tumours of the trachea and main carina apped to be well suited to laser photoresection. ${ }^{28}$ The patient reported here was nearly asphyxiated by his tumour but obtained immediate and sustained relief from one treatmento which gave us time to evaluate the resectability of the tumour and assess the potential for curative surgery.

Although this patient could have been treated wi emergency surgery alone, the chances of his surviving woulf have been considerably reduced. The clearance of the airway with the laser facilitated the preoperative treatment of his chest infection and obviated the need for prolonged sterog treatment, which might have impaired postoperative healing Radiotherapy would not have been as effective in these cis cumstances and in addition would have prejudiced sub sequent tracheal surgery. 

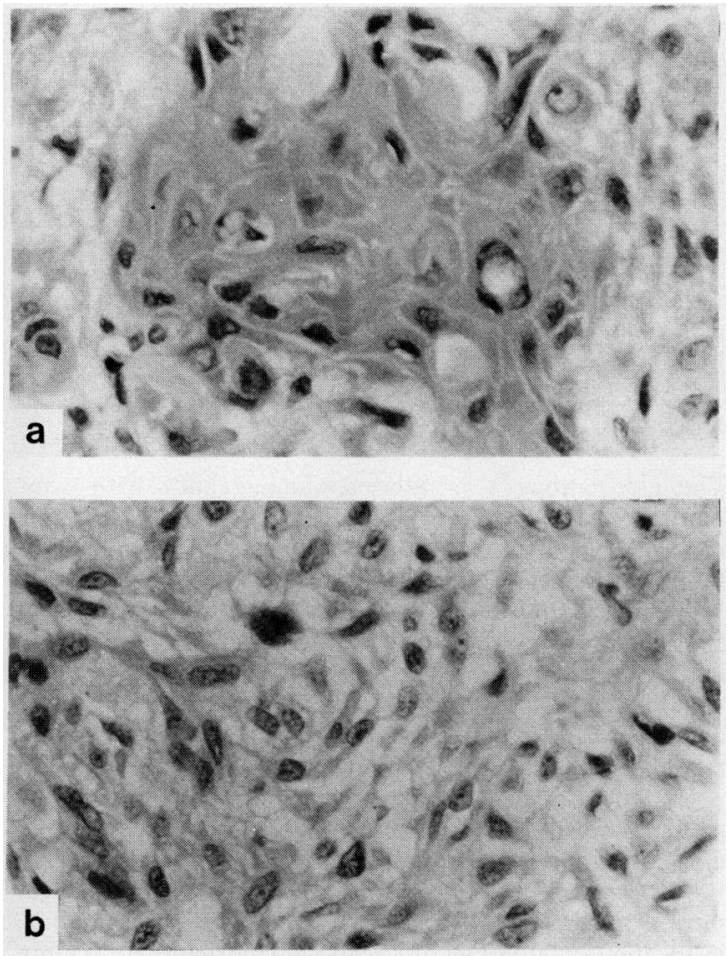

Fig 1 (a) Area of squamous differentiation within tumour. (b) Myxoid spindle cell area within tumour. (Haematoxylin and eosin stain; $\times 380$.)

Pleomorphic adenomas are known to occur in the trachea and, although classified as benign tumours, they may grow into the lumen and obstruct the airway. A review of the few reported cases would suggest that surgical removal is an effective treatment. ${ }^{9}$ There have been no previous reports of malignancy arising in these tumours in the trachea and so the prognosis in this patient is uncertain. Nevertheless, the five year survival in patients with malignant mixed tumours of salivary glands has been estimated as $55 \cdot 7 \%{ }^{10}$ and so it is possible that this patient has been cured.

We would like to thank Drs W A H Bodger and B Cocking for referring this patient for laser treatment.

\section{References}

1 Hetzel MR, Millard FJC, Ayesh R, et al. Laser treatment for carcinoma of the bronchus. Br Med J 1983;286:12-6.

2 Hetzel MR, Nixon C, Edmonstone WM, et al. Laser therapy in 100 tracheobronchial tumours. Thorax 1985;40:341-5.

3 Makin CA, Bobrow LG, Bodmer WF. Monoclonal antibody to
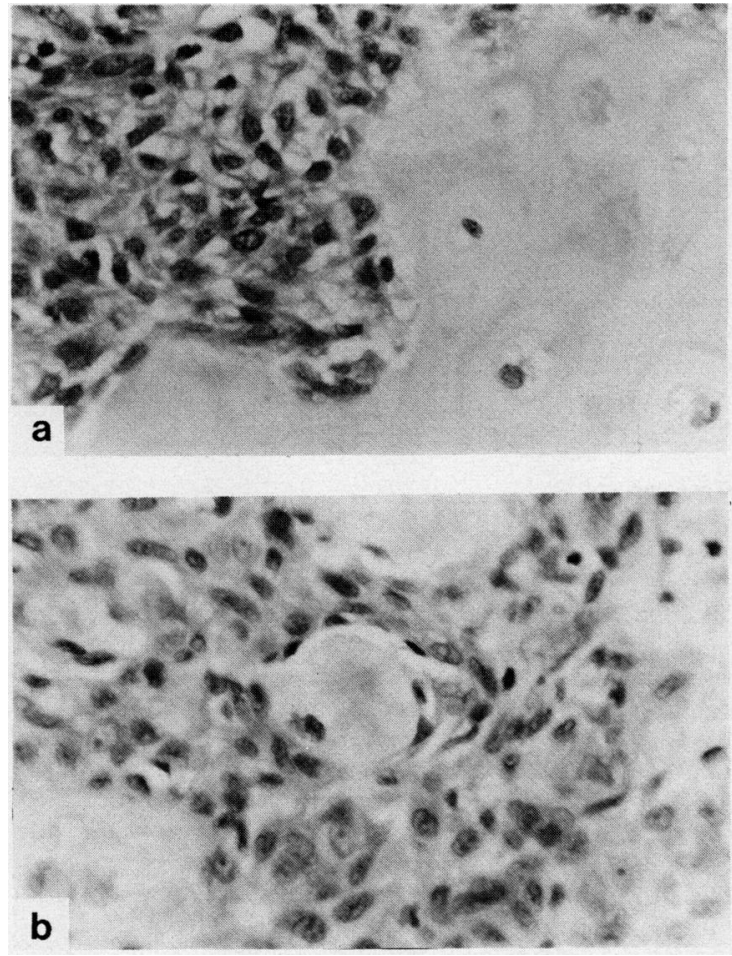

Fig 2 (a) Tumour cells invading tracheal cartilage. (b) Tyrosine crystal within tumour. (Haematoxylin and eosin stain; $\times 380$.)

cytokeratin for use in routine histopathology. J Clin Pathol 1984;37:975-83.

4 Moore BW. A soluble protein characteristic of the nervous system. Biochem Biophys Res Comm 1965;19:739-44.

5 Franke WW, Schmid E, Winter S, Osborn M, Webber K. Widespread occurrence of intermediate-sized filaments of the vimentin type in cultured cells from diverse vertebrates. Exp Cell Res 1979;123:25-46.

6 Erlandson RA, Cardon-Cardo C, Higgins PJ. Histogenesis of benign pleomorphic adenoma (mixed tumour) of the major salivary glands. An ultrastructural and immunohistochemical study. Am J Surg Pathol 1984;8:803-20.

7 Batsakis JG. Tumours of the major salivary glands. Tumours of the head and neck. Clinical and pathological considerations. 2nd ed. Baltimore: Williams and Wilkins, 1979:1-76.

8 Laforet EG, Berger RL, Vaughan CW. Carcinoma obstructing the trachea: Treatment by laser resection. $N$ Engl $J$ Med 1976;294:941.

9 Ma CK, Fine G, Lewis J, Lee MW. Benign mixed tumour of the trachea. Cancer 1979;44:2260-6.

10 Hickman RE, Cawson RA, Duffy SW. The prognosis of specific types of salivary gland tumours. Cancer 1984;54:1620-4. 